\title{
ТРНКААФНАЯ ЭКОНОМนКА
}

УДК 334.021

С.Г. Важенин, канд. экон. наук,

В.В. Сухих, канд. экон. наук, ${ }^{1}$ г. Екатеринбург, Россия

\section{СПЕЦИФИКА ДОВЕРИЯ КАК КОНКУРЕНТНОЙ ЦЕЛИ В ЭКОНОМИКЕ}

Усиление конкуренции заставляет компании искать новые конкурентные преимущества. Так как обилие информации и предложений на рынках затрудняет потребителям и потенциальным партнерам выбор определенного товара или конкретной компании, то важнейшим конкурентным преимуществом становится уникальный узнаваемый образ компании для потребителей и партнеров, который способен выделить компанию и ее товары или услуги среди прочих многочисленных предложений на рынке. Этот образ во многом определяется доверием к компании. Доверие становится важнейшим ресурсом, конкурировать за который приходится не только компаниям, но и странам. В статье дается определение понятия «конкуренция за доверие» и рассматривается специфика доверия как конкурентной цели в экономике. Специфика определяется тем, что доверие - это поведенческая характеристика, оно имеет не только экономическое, но и психологическое значение. Доверие иррационально, это взаимное чувство и требует соответственно для возникновения взаимных усилий. Невозможно будет компании добиться доверия со стороны других, если сама компания при этом отказывает в доверии своим партнерам и потребителям. Доверие, будучи иррациональным ожиданием, неразрывно связано с риском. Всегда существует непредусмотренная возможность разрушения доверия к компании. Доверие легко исчезает, зато оно способно восстанавливаться в отличие от других истраченных ресурсов. При этом доверие может быть неограниченным ресурсом, доступным сразу нескольким конкурентам, что создает основу для их сотрудничества. Конкурентное сотрудничество позволяет компаниям получать прибыль от увеличения доверия к отрасли в целом, избегая риска потерь в конкурентной борьбе. Также в статье рассматривается специфика измерения доверия, оцениваются состояние и перспективы конкуренции за доверие в российской экономике. Анализ опыта построения доверия в западных компаниях позволил дать несколько рекомендаций по оптимальным тактикам успеха в конкурентной борьбе за доверие.

Ключевые слова: доверие, конкуренция, конкурентная цель, коопетиция, сотрудничество.

\section{Актуальность темы исследования}

Благодаря глобализации и развитию информационных технологий, конкуренция стремительно «расползается», как вирус, во все сферы экономической деятельности. При этом конкурентные отношения усложняются и изменяются, совмещая в себе соперничество и конкурентное сотрудничество. Обилие информации и предложений на рынках затрудняет потребителям и потенциальным партнерам выбор определенного товара или конкретной компании, а также делает их более требовательными. Прежние конкурентные преимущества теряют свое значение. Как справедливо указы- вает М. Портер, наличие рабочей силы, капитала или сырья не определяет успех компании, поскольку указанные ресурсы стали широкодоступными [1, с. 23]. Конкуренция уже давно вышла за пределы состязания в цене и качестве товара. Джоан Робинсон

\footnotetext{
${ }^{1}$ Важенин Сергей Григорьевич - кандидат экономических наук, заведующий сектором Института экономики Уральского отделения РАН, г. Екатеринбург, Россия (620014, г. Екатеринбург, ул. Московская, 29); е-таil: svazhenin@mail.ru.

Сухих Василий Валентинович - кандидат экономических наук, научный сотрудник Института экономики Уральского отделения РАН, г. Екатеринбург, Россия (620014, г. Екатеринбург, ул. Московская, 29); e-mail: vsh-sh@yandex.ru.
} 
еще в 1933 г. отмечала: «В действительности покупателя интересуют не только цены, назначаемые конкурирующими производителями на товары; он руководствуется и многими другими соображениями. Конкурирующие производители состязаются друг с другом в качестве своих товаров, в предоставляемых покупателям льготах и в рекламе точно так же, как и в ценах» [2, с. 136-137]. Поэтому, помимо традиционных конкурентных преимуществ, улучшающих или удешевляющих предлагаемые товары и услуги, компании активно ищут новые.

Важнейшим конкурентным преимуществом становится уникальный узнаваемый образ компании для потребителей и партнеров, который способен выделить компанию и ее товары или услуги среди прочих многочисленных предложений на рынке. Компании, продолжая соперничать за ресурсы, сырье и контракты, теперь все больше конкурируют не своими товарами и знаниями, а своими образами, своей лучшей репутацией $[3,4]$, завоеванным доверием к себе, перенося конкуренцию в сферу нематериальных активов, стремясь не только пробудить интерес потребителя, но и удержать его в качестве клиента конкретной компании.

Компании, как и люди, в своей деятельности ставят перед собой определенные цели и разрабатывают способы их достижения. Действия компаний, их тактика и стратегия напрямую зависят от поставленных ими целей. После определения важности доверия естественно его «поднятие» в системе координат ценностей и предпочтений компании, выдвижение доверия в качестве первоочередных конкурентных целей. Прежде конкурентными целями были монополия, цена и качество товара, редкие и малодоступные ресурсы. Теперь парадигма развития современной экономики, требующая развития брендов и торговых марок, правильного позиционирования товара и завоевания рынков через конструирование механизмов влияния на мнение потребите- ля и партнеров, делает доверие ценнейшим ресурсом, борьба за который достигает такой же остроты, как прежние конкурентные войны за золото или нефть. Осознавая ценность доверия, компании все чаще выбирают завоевание доверия к себе в качестве конкурентной цели.

\section{Доверие как первоочередная конку- рентная цель}

Конкурируют за доверие не только компании, но и регионы, страны и экономические союзы. Недаром в мемуарах премьерминистра Сингапура Ли Куан Ю [5] доверию уделено немало места: «Нашим самым ценным активом было доверие людей»; «Если бы я должен был описать одним словом, почему Сингапур преуспел, то этим словом было бы “доверие” (confidence)»; «Доверие к нашей честности и компетенции собиралось по крохам. История нашего финансового центра - это история того, как мы укрепляли доверие к Сингапуру как к месту, где бизнес ведется честно» и т.д.

Завоевание доверия приносит ощутимую прибыль. Как утверждает практик и теоретик бизнеса Стивен Кови-младший: «Нет экономики более прибыльной, чем экономика доверия» [6, с. 3]. Специалисты международного агентства Edelman в своем социологическом исследовании Trust Barometer 2011 по измерению уровня доверия к бизнесу, брендам и различным общественным институтам доказали, что доверие является очень важным фактором для восприятия информации о компании. В ведущих странах Запада, таких как США и Великобритания, четверть респондентов признались, что им для того чтобы поверить информации о компании, нужно ее услышать 6 и более раз. Однако если фирма не пользуется доверием, то 57 \% респондентов поверят негативной информации, услышав ее всего 1-2 раза [7]. Поэтому, хотя завоевание доверия и несет за собой значительные издержки и риски, компании охотно идут на такие жертвы, как дорого- 
стоящие рекламные компании, постоянный мониторинг мнения потребителей и поставщиков и многолетняя работа с общественным мнением. Люди, не доверяющие самой эффективной компании, способны сделать ее неэффективной, несмотря на всю ее стратегию и тактику, несмотря ни на какие огромные вложения в качество и удешевление товара.

Особенно наглядно выгодность доверия проявляется при оценке стоимости торговых марок компаний. Британская исследовательская компания Millward Brown определяет торговые марки как инструменты социального влияния, генерирующие прибыль. В ряде случаев до 90 \% стоимости компании составляют стоимости ее торговых марок. По мнению экспертов Millward Brown, самой дорогой торговой маркой 2014 г. стал Google, сумевший обогнать многолетнего прежнего чемпиона Apple. Марку лидера интернет-бизнеса оценили в \$158,843 млрд, против \$113,669 млрд в 2013 г. Стоимость бренда Google за минувший год выросла почти на 40 \%, a стоимость бренда Apple за минувший год упала на 20 \% и составила \$147,880 млрд против \$185,071 млрд в 2013 г. Третью и четвертую строчки рейтинга также заняли бренды компаний из высокотехнологичной сферы - IBM (\$107,541 млрд) и Microsoft (\$90,185 млрд) [8].

Из-за столь высоких финансовых оценок брендов и репутации доверие стремительно превращается для экономистов в один из популярных объектов изучения, свидетельством чему является активная публикация работ, рассматривающих его разные аспекты, анализирующие методики измерения доверия и стратегии его достижения [9-13]. Зарубежные и отечественные ученые едины в оценке значимости доверия. К примеру, Дж. Ходжсон утверждает: «Доверие и связанные с ним другие, не подлежащие контракту ценности, не просто эффективны и удобны; даже рыночная система, ввиду присущих ей сложности и неопределенности, в принципе не может без них функционировать» [14, с. 246].

Г. Клейнер отмечает: «Доверие является своего рода “воздухом” экономики; оно пронизывает все ее элементы» [15, с. 16]. Глобализация, в частности ее информационные и логистические достижения, позволившие информации и товарам быстро перемещаться по миру, привела сперва к интернационализации доверия [16], а затем и к расширению сфер, где идет конкуренция за доверие. Вместе с тем подобной конкуренции уделяется крайне мало внимания, равно как и специфике доверия как конкурентной цели, хотя, на наш взгляд, именно этой спецификой объясняются многие трудности завоевания и удержания доверия компаниями.

По нашему мнению, «конкуренциия за доверие» - это поведение субъекта рынка в экономическом пространстве, ориентированное на завоевание и удержание доверия к себе со стороны как можно большего числа других субъектов рынка, в результате чего создается конкурентное преимущество в виде благоприятного и узнаваемого образа субъекта, а также формируется основа для взаимовыгодного сотрудничества с партнерами по бизнесу, с потребителями и органами управления.

В данной работе мы выделяем следующие специфические черты доверия как конкурентной цели.

Доверие является поведенческой характеристикой

Этот факт объясняет всю непостоянность доверия и сложность его завоевания. Ю.Я. Ольсевич отмечает, что большинству субъектов рынка присуще последовательное поведение, диктуемое инстинктом доверия, врожденной потребностью людей доверять себе подобным и социуму $[17$, с. 15]. Однако если потребитель и партнер действительно имеет склонность кому-то доверять, несмотря на то, что порой их доверие будет обмануто, то компаниям вовсе 
не приходится пассивно ждать, что доверять станут именно им. На рынке всегда предостаточно игроков, нуждающихся в доверии для сбыта своих товаров и предоставления услуг.

Компаниям приходится конкурировать за доверие потребителей, которые могут кардинально отличаться по своему мировоззрению и оценкам предлагаемого компанией имиджа. Компании следует смириться, что одним и тем же способом завоевать доверие абсолютного большинства потребителей заведомо не удастся, для каждой группы потребителей и партнеров нужен будет особый подход. При этом доверие взаимное чувство и требует соответственно для возникновения взаимных усилий. Каждый потребитель в той или иной степени склонен к доверию, и при этом сам нуждается в доверии. Невозможно будет компании добиться доверия со стороны других, если сама компания при этом отказывает в доверии своим партнерам и потребителям.

Ценность доверия в том, что оно имеет не только экономическое, но и психологическое значение, без учета которого невозможно рассматривать экономические отношения, так как люди, в них участвующие, не могут быть свободны от пристрастий, симпатий и антипатий. Лауреат Нобелевской премии по экономике за 1998 г. Морис Алле утверждал: «Я рассматривал человеческую психологию как фундаментальный фактор, независимо от того, идет ли речь о теоретическом экономическом анализе или о прикладной экономике» [18, с. 80]. Применительно к доверию в экономике это особенно верно.

Экономические отношения во многом зависят от потребности человека во взаимоотношении и сотрудничестве с другими людьми. Можно говорить о потребности людей в доверии и потребности доверять. Стивен Кови-мл. уверен: «Люди хотят, чтобы им доверяли. Они отзываются на доверие. Они расцветают, когда им доверяют» $[6$, с. 50]. Потребность в доверии, желание его завоевать с древнейших времен влияла на человеческую деятельность, в частности, заставляя делать более совершенные орудия труда. Антрополог Пенни Спикинс (Penny Spikins) из университета Йорка выдвинула гипотезу о том, что функционально неоправданное совершенство каменных орудий связано с тем, что древние люди, изготавливая такие орудия, пытались заработать репутацию и доверие общества. Способность к скрупулезной работе, как она считает, должна была показать, что изготовителю топора можно доверять. В качестве аргументов в пользу своей гипотезы П. Спикинс выдвигает наблюдения за шимпанзе, в сообществе которых, по ее словам, тоже можно наблюдать «зачатки взаимоотношений на основе доверия» [19].

Данная гипотеза вполне правдоподобна, если учесть, что в последующей истории человечества демонстрация мастерства перед потенциальными заказчиками не только обеспечивала ремесленнику или художнику заказы, но и поднимала его социальный статус через признание его умения обществом. Конкурировать за доверие приходилось не только в ремесленном производстве, но и в торговых делах, где репутация становилась жизненно необходимым фактором сохранения дела через удержание поставщиков и покупателей, а также его развития через увеличение доступности кредита и числа потенциальных партнеров [20-21]. Своеобразными центрами конкуренции за доверие становились ярмарки и выставки, где демонстрировались лучшие изделия, сравнивалось не только качества товара, но и способность продавца держать свое слово.

Французский социолог Ф. Буари особо подчеркивает, что из-за психологической значимости доверия для людей, они не могут долго сотрудничать в условиях недоверия: «Приговорить группу к вечному недоверию - все равно, что приговорить ее к смерти, потому что никакая группа, будь то компания, государство или общество в целом, не способна жить без внутреннего 
скелета и без внешней сети доверительных отношений», [22, с. 56]. Поэтому, прилагая все усилия чтобы получить доверие к компании, работающие в ней люди стремятся не только к финансовой выгоде, но и к психологическому комфорту, возникающему от чувства доверия к ним потребителей и партнеров. Порой владельцы и сотрудники компании могут рассматривать доверие к своей фирме как самоцель конкурентной борьбы, отводя финансовой выгоде подчиненное положение. Особенно это характерно для семейных компаний с многолетней историей. Владельцы подобных компаний рассматривают репутацию своей компании как репутацию семьи, что делает доверие и недоверие к компании не вопросом прибыли, а вопросом личного достоинства.

Доверие иррационально и изменчиво, не фиксируется, крайне сложно передается, при этом легко исчезает

Доверие само по себе оптимистично и связано с ожиданием добросовестности от компаний и людей, даже несмотря на то, что у доверяющего нет уверенности в том, что его доверие не будет обмануто. Доверие также дает «подушку безопасности», когда доверяющий способен простить некоторые ошибки со стороны партнеров, уверенный в их исправлении и недопущении в будущем. Но это все равно не позволит компаниям, конкурирующим за доверие, быть излишне успокоенными, когда доверие будет завоевано.

Доверие, будучи иррациональным ожиданием, неразрывно связано с риском. Всегда существует непредусмотренная возможность разрушения доверия к компании, даже если компания изо всех сил старается его сохранить. Причиной могут быть как ошибки самой компании, так и внешние факторы, нарушившие возможность компании выполнять свои обязательства. Формируясь и укрепляясь довольно длительное время, добытое с огромным трудом, доверие может быть утрачено в один миг. Как пове- денческая характеристика доверие трудно поддается контролю. Хорошо изучила это на своем примере компания Microsoft, недоверие к которой многих пользователей и даже государственных органов не зависит от качества и цены продукции компании, а вызвано сомнениями в сохранении приватности данных и уверенности клиентов в недобросовестной конкуренции компании для завоевания рынка.

Компании, покупатели и партнеры не могут юридически оформить свои сложившиеся отношения доверия, получить обещания доверять в будущем или гарантий лояльности ко всем товарам компаний, завоевавшей доверие для какого-то одного предложения. Доверие невозможно автоматически продлить или передать другому. Даже такой давно институционально оформленный процесс, как продажа торговых марок, дает риск снижения стоимости продаваемого бренда из-за смены владельца. Поэтому завоеванный компанией капитал доверия, пусть и оформленный в виде зарегистрированной торговой марки, в полной мере может быть реализован только самой же компанией. В этом доверие принципиально отличается от прочих ресурсов компаний, материальных и человеческих.

Чтобы снизить риски потери доверия, западные компании все больше усилий вкладывают в создание социального капитала, который трактуется как сеть социальных отношений, влияющих на индивидуальное поведение. Репутация компаний зависит от охвата социальных сетей, с помощью которых ее можно пропагандировать, а уже с помощью репутации становится возможным обеспечить участие других заинтересованных сторон в предпринимаемых компанией действиях [23, с. 41]. Через социальный капитал компания снижает риски, неизбежно возникающие при разрыве между корпоративной стоимостью и стоимостью бренда. Высокая стоимость брендов Apple и Google будет быстро обрушена, если компании потеряют доверие потребителей и им не 
поможет никакое государственное вмешательство. Этот факт заставляет компании быть социально ответственными, завоевывая и поддерживая доверие общества всеми возможными средствами.

Доверие может быть неограниченным ресурсом, доступным сразу всем конкурентам, что создает основу для их сотрудничества

По определению В.В. Радаева, конкуренция - это действия двух и более участников рынка, нацеленные на получение одного и того же ограниченного ресурса, доступного при определенных усилиях с их стороны [24, с. 48]. Доверие же может быть неограниченным ресурсом и тем не менее быть целью конкурентной борьбы. Один и тот же человек, одна и та же компания способны доверять всем участникам рынка, даже если они являются конкурентами между собой. В этом случае решение о выборе принимается либо через определение доверия как большего или меньшего через сравнение отношений к конкурентам, либо же доверие будет выступать лишь одним из критериев выбора поставщиков товаров и услуг, а решающими станут другие факторы - цена товара, его качество, скидки и т.д. Пользуясь спортивной терминологией, можно указать, что доверие и репутация позволяют компании пройти в «высшую лигу», попасть в фавориты, из которых потребитель выбирает себе поставщиков и партнеров, так как доверие и репутация, которые компания обеспечила себе работой с прежними клиентами, снижают риски для новых клиентов, получающих гарантии добросовестности.

Доверие является ресурсом вполне доступным сразу нескольким конкурентам, в отличие от финансовых и материальных ресурсов, получение которых одной компанией означает, что другие их не получат или получат ограниченно. Поэтому оно может служить основой для сотрудничества конкурирующих компаний. С целью дости- жения преимуществ в доверии компания может пойти двумя путями. Первый предполагает сужение доверия потребителя до продуктов исключительно одной компании, что достигается созданием и укреплением торговых марок. Этот путь ведет к повышению соперничества с другими компаниями, которые станут нести убытки от чужой победы в конкуренции за доверие. Второй предполагает увеличение общего доверия к товарам определенной отрасли, что приносит выгоду всем производителям данного товара за счет увеличения спроса на их продукцию. Этот подход открывает преимущества конкурентного сотрудничества и приобретает все большую популярность в развитых странах.

Конкурентное сотрудничество (коопетиция) [25] позволяет наладить взаимодействие конкурентов на общее благо развития отрасли, добиться взаимовыгодных правил игры, обеспечить общие интересы, создать и поддержать доверие партнеров, поставщиков и покупателей не к конкретной компании, а сразу к отрасли или отдельным технологиям. Выгоду от коопетиции и повышения доверия получают все участвующие в ней компании. К примеру, увеличение безопасности движения из-за улучшения качества дорог поднимет доверие потребителей к автомобильному транспорту и повысит продажи машин всех производителей. Правда, и потерять доверие участники рынка могут все вместе, как это произошло после терактов 11 сентября 2001 г. с авиаперевозчиками.

Невозможность сохранить доверие к отрасли в целом при подрыве доверия к отдельным работающим в ней компаниям заставляет конкурентов вместе вырабатывать меры по сохранению доверия. На это, в частности, указывал Ричард М. Локке в своем исследовании доверия на примере производства сыра. Мошенничество отдельных производителей итальянского сыра буффало-моцарелла с качеством продукта неизбежно сказывалось в снижении 
доверия ко всем производителям сыра, так как большинство потребителей связывало сыр не с конкретным производителем, а с его географическим происхождением, так что все местные производители страдали в случае утраты доверия к продукту в равной мере. Это заставило компании - производители сыра объединиться ради сохранения доверия в контроле за качеством продукта $[26$, с. 17]. Подобная коопетиция не ликвидирует конкурентную борьбу за потребителя, но уменьшает потери всех участников рынка от недобросовестности отдельных фирм, поддерживая высокую марку и репутацию продукта.

Новые отношения компаний ни в коей мере не уничтожают конкуренцию, но вводят ее в ограничительные рамки, минимизируя риски и взаимные убытки. Ставка на снижение рисков определила отказ от конкурентных войн как от чрезмерно рискованных предприятий. Непредсказуемость будущего потребовала сотрудничества в его создании. Переход к конкурентному сотрудничеству был облегчен и тем фактом, что, как верно указывает Ю.Б. Рубин, субъекты малого и мельчайшего предпринимательства, составляющие абсолютное большинство участников всех локальных и национальных рынков, никогда не помышляют о своей монополии [27, с. 58]. Они готовы жить в условиях конкуренции и сотрудничать с конкурентами для достижения взаимовыгодных целей.

При этом и крупные фирмы становятся все больше заинтересованы в конкурентах и не только чтобы копировать их успехи или учиться на ошибках. Не случайно такой знаток конкуренции, как М. Портер, считает, что добросовестные участники рынка заинтересованы в «полезных конкурентах» не меньше, чем в надежных партнерах и постоянных клиентах. По мнению М. Портера, наличие правильных конкурентов во многих отраслях не только не ослабляет, но еще более укрепляет конкурентные позиции компании. Конкуренты очень выгодны с точки зрения стратегии - они помогают в развитии рынка и его защите от вторжения новых конкурентов, дают дополнительную мотивацию к развитию, снижают риск антимонопольных мер, улучшают позиции в переговорах с партнерами и покупателями, которым есть с чем сравнивать услуги компании. С конкурентом можно разделить затраты на развитие рынка, снизить риски для покупателей в процессе развития новых технологий, договориться о помощи в стандартизации и узаконивании технологии, в укреплении имиджа отрасли в целом и т.д. Такие «хорошие» конкуренты, по мнению М. Портера, вынуждают компанию к активным действиям, но в то же время взаимодействие с ними способствует созданию стабильного и взаимовыгодного равновесия в отрасли, не вступая в затяжную войну [28, с. 292-306]. Чем выше доверие у компании - тем больше «хороших» конкурентов она сможет приобрести и тем устойчивей будет ее положение на рынке.

Таким образом, эффективная конкуренция невозможна без сотрудничества. Если конкуренты сообща или по отдельности прилагают усилия, направленные на расширение рынка и удовлетворение потребностей, они в конечном счете способствуют всеобщей результативности. Когда конкуренты сосредоточены на лучшем обслуживании клиента (снижение цен, защита окружающей среды и т.д.), все оказываются в выигрыше [29, с. 56]. При этом качество обслуживания будет повышаться не за счет конкуренции, а за счет сотрудничества, в архитектуре которого особо значимым выступает доверие.

\section{Доверие способно восстанавливаться в отличие от многих других ресурсов}

Когда доверие не оправдывается и теряется, оно все же способно восстановиться заново. Ошибочно растраченные финансовые и материальные ресурсы чаще всего невозможно вернуть, утраченное же доверие можно вновь приобрести, пусть и 
приложив для этого немало усилий. Это весьма значимо, так как, даже признав важность доверия и определив его в качестве конкурентной цели, компания может проиграть борьбу за доверие и столкнуться с проблемой его возврата. Компания может также изначально оказаться в невыгодном положении в конкуренции за доверие, если прежде не уделяла внимание доверию, что привело к его потере. И что совсем уж не редкий случай, компания может оказаться пострадавшей из-за чужих ошибок и чужой вины, снизившей доверие к отрасли или даже экономике в целом.

Компаниям, конкурирующим за доверие, следует помнить, что у потребителя может быть своя история доверия, включающая в себя как приятные воспоминания об оправданности доверия, так и горькие уроки обмана доверия, заставившие его более осторожно подходить к вопросу, стоит ли доверять кому-либо. Подобная история может быть у целых обществ. К примеру, после первой эйфории доверия к рекламе и частным компаниям в России начала 1990-х гг. наступило, после множества афер и обманов, время тотального недоверия и эту поведенческую характеристику россиян, недоверие к банкам, к органам власти и муниципального управления не удалось преодолеть до сих пор. Склонность к доверию и само доверие выше там, где многолетняя стабильность и опыт успешности доверия приводит к привычке доверять. Развитые страны Запада демонстрируют стабильно высокое доверие в экономике и обществе, в то время как развивающиеся страны, отчаянно нуждаясь в высоком уровне доверия, сталкиваются с замкнутым кругом недоверия, так как население и субъекты рынка не привыкли доверять, имеют негативную историю доверия и склонны с большой осторожностью доверять кому-либо в будущем [30].

Поэтому компаниям могут создать трудности в завоевании доверия чужие обманы и негативный опыт доверия в прошлом их новых партнеров и потребителей. Вместе с тем не стоит сбрасывать со счетов и те случаи, когда негативный опыт доверия связан именно с той же компанией, которая теперь настроена вновь завоевать доверие к себе. Неисполнение своих обязательств, плохое качество и высокая цена товара, ошибки в стратегии развития компании - все это будут создавать негативную историю доверия, стереть которую из памяти партнеров и потребителей будет невозможно. Однако примеров успешного восстановления доверия к компаниям и даже целым странам все же достаточно много, чтобы, потерпев поражение в завоевании доверия, компания не могла бы рассчитывать на успех в конкуренции за доверие в будущем.

В российской истории ярким примером восстановления доверия является политика советского государства после Октябрьской революции. Большевики приложили максимум усилий по завоеванию доверия народа к своей партии и своим планам. В.И. Ленин в работе «Очередные задачи Советской власти» (апрель 1918 г.) отмечал: «Первой задачей всякой партии будущего является - убедить большинство народа в правильности ее программы и тактики». Лишь после этого выполнима вторая задача - завоевание политической власти, а потом и третья - организация управления страной. В.И. Ленин с гордостью утверждал: «Мы, партия большевиков, Россию убедили» [31, c. 172].

Большевики убедили страну прежде всего в том, что предлагаемые ими экономические планы построения социализма вполне реальны и могут быть выгодны всем трудящимся. При этом им удалось завоевать не только доверие к себе большей части населения, но и доверие иностранных партнеров, свидетельством чему стали совместные предприятия и концессии, созданные в годы НЭПа. Немалую роль доверие сыграло в восстановлении национальной валюты с введением золотого червонца. Общенародный порыв был свой- 
ственен всем грандиозным проектам советской власти от Магнитки и Днепрогэса до ямальских строек и БАМа 1970-80 гг. Вера в миссию поколений объединяла людей, отсюда и невиданное доверие к власти, подкрепляемое несомненными успехами советской промышленности.

Хорошим примером успешного восстановления доверия к стране и ее экономике целиком является политика Людвига Эрхарда, министра народного хозяйства ФРГ с 1949 по 1963 г. и канцлера ФРГ в 19631966 гг. Газета «Торонто стар уикли» посвятила 17 марта 1956 г. подробную статью Л. Эрхарду, где было отмечено: «Почти все сегодня признают, что постоянный экономический прогресс Федеративной Республики стал возможен благодаря доверию, оказываемому многими немцами социальному рыночному хозяйству Эрхарда». В этой же статье цитировался ответ Л. Эрхарда на вопрос, в чем он видит свое главное достижение. Л. Эрхард ответил: «Нацисты обманули весь мир. Своим лукавством такие люди, как Функ, разрушили доверие всего мира к немецкому хозяйству. Я горжусь тем, что нам теперь удалось снова восстановить доверие мира к Германии» [32, c. 263-264].

Более современный пример восстановления доверия к экономике продемонстрировала Южная Корея. В период экономического кризиса в Юго-Восточной Азии в 1997-99 гг. правительство этой страны оказалось не в состоянии выбраться из валютно-финансового кризиса и расплатиться с внешними долгами. Доверие к стране было настолько низким, что не было возможности получить новые кредиты. Однако правительство смогло добиться доверия к своей экономической политике со стороны населения. Люди стали отдавать свои сбережения, лишь бы помочь стране. Как сообщали информагентства в первой половине 1998 г., за два с половиной месяца граждане Южной Кореи собрали для государства 225 т золота, которое переплавили в слитки и продали за границей. Это помогло Южной Корее частично расплатиться с внешним долгом, превышающим \$150 млрд. В общенациональной компании по «спасению экономики» приняла участие каждая четвертая корейская семья.

Преодолев с помощью доверия населения внутренний кризис, правительство Южной Кореи восстановило свое «лицо» перед внешним миром одной из самых успешных PR-компанией в мировой практике. За программу «Восстановление доверия к южнокорейской экономике» Министерство финансов и экономики Южной Кореи совместно с агентством Burson Marsteller получило престижную премию в области PR «Серебряная наковальня» за 1999 г. [33].

Примером успеха отдельной компании в восстановлении доверия является успех компании Kodak по созданию доверия на новом этапе деятельности компании (1997-1999 гг.). Kodak сумел не только разработать новую стратегию восстановления доверия к компании, но и блестяще воплотить ее на протяжении нескольких лет, за что компания получила премию «Серебряная наковальня» за 1999 г. [34].

Неудачи в построении доверия и потеря доверия к отдельным компаниям могут сказаться на экономике в целом, запустив цепь разрушения прежних доверительных отношений. К примеру, на фоне кризиса доверия, вызванного вскрывшимися фактами мошенничества крупных американских компаний в начале 2000-х гг., экономисты из Института Брукингса спрогнозировали, что результаты спада деловой активности, вызванного потерей доверия инвесторов, будут оказывать мощное воздействие на американскую экономику, снижая потребительские расходы и инвестиционную активность. Прогнозируемое падение производства из-за снижения инвестиций определялось в \$35 млрд в течение года, $\$ 62$ млрд в течение следующих двух лет; \$166 млрд в течение следующего десяти- 
летия. Столь долговременные последствия были связаны с тем, что в общественном мнении источник скандала находился в центре, а не на периферии системы $[23$, c. 32$]$.

Для решения системного кризиса доверия пришлось объединять усилия многих стран. Всемирный экономический форум в Давосе в 2003 г. прошел под лозунгом «Построение доверия». «Вереница корпоративных скандалов, произошедших в 2002 г., сильно подорвала уровень доверия к компаниям в мире», - признавалось в приветственном слове к форуму. При этом негативное влияние пошло далеко за пределы корпоративного сектора. Опрос 36 тыс. человек в 47 странах, проведенный перед форумом, показал, что широко распространенным явлением стала потеря доверия к правительству. При этом 48 \% опрошенных «мало доверяют или совсем не верят» в транснациональные корпорации, а 52 \% с таким же скептицизмом отзываются о крупных национальных компаниях. Ключевыми пунктами форума в контексте «построения доверия» стали пять элементов: корпоративные проблемы, глобальная экономика, глобальное управление, безопасность и геополитика, доверие [35]. Однако планируемого восстановления доверия и урегулирования конфликтов достичь не удалось. Эксперты даже не смогли с уверенностью судить, когда именно доверие будет восстановлено до предкризисного уровня.

В 2010 г. на форуме в Давосе вновь признали, что, хотя без доверия рыночная экономика не может функционировать, общественное доверие к бизнесу является слабым и угрожает рухнуть целиком [36]. С 2013 г. при Всемирном экономическом форуме стала действовать постоянная программа «Leadership, trust and performance equation». В целях программы заявлено, что так как доверие является основным компонентом в обеспечении конкурентоспособности, то данный проект поможет бизнес-сообществам в построении доверия через определение важнейших аспектов доверия, через обоснование важности инвестирования в доверие и через примеры конкретных действий, которые могут помочь компаниям строить доверие [37]. При всех подобных программах стоит отметить, что успех в конкурентной борьбе за доверие при всей важности сотрудничества во многом результат индивидуальных усилий компаний и стран, так как принятие на себя ответственности за качество обслуживания клиентов и верность выполнения обязательств перед партнерами и не может быть коллективным. Конкретные действия одной компании принесут больше пользы в восстановлении доверия, чем коллективные заверения в верности неким абстрактным принципам ведения дел, которым на практике могут не следовать.

\section{Специфика оценки уровня доверия}

Определяя доверие в качестве конкурентной цели, компании сталкиваются с проблемой определения наилучшей стратегии достижения доверия. Первоочередной задачей при этом станет измерение доверия в качестве точки отчета успешности или провала конкурентной борьбы за него. Невозможно вести конкурентную борьбу, не зная, приводит ли выбранная стратегия к успеху или ее надо срочно менять.

Компании в ходе конкурентной борьбы за доверие должны постоянно оценивать его распространение и влияние на партнера. Результатом измерения будет знание процентного соотношения в обществе или отдельной группе потребителей или партнеров тех, у кого присутствует доверие к компании, и тех, кто ей не доверяет. Если число доверяющих постепенно увеличивается, значит, стратегия компании верна, если уменьшается - время бить тревогу и выяснить причины падения доверия.

Самой главной трудностью подобного измерения будет связь доверия с психологией человека. Доверие само по себе иррационально и зачастую необъяснимо. Если 
доверие, основанное на надежности, доверие, основанное на знании, и тем более доверие, основанное на расчете, являются проявлением осознанной позиции, то уже доверие, основанное на эмоциональной приязни, и доверие, основанное на вере, могут быть результатом неосознанного решения [38, с. 476-477]. Поэтому сам человек может не вполне четко осознавать наличие у себя доверия или недоверия. Однако они будут проявляться в его поведении и через анализ поступков будут выявлены.

Из-за этой особенности доверия выявить и измерить его наличие можно двумя способами. Первый - спросить самого человека. Второе - проанализировать его действия. Второй способ, возможно, более точен, так как человек может либо обмануть исследователя (вольно или невольно), либо искренне заблуждаться. Действия же человека выдают его истинные взгляды. Он может заявлять о доверии к партнеру, но если одновременно с этим он не согласен заключать сделки без надлежащего оформления контракта и не готов к открытости в экономических отношениях, то можно заключить, что провозглашаемое доверие отсутствует.

Давно и успешно применяются в практике взаимоотношений в группах и организациях способы выявления доверия через составление специальных опросников по разным методикам, а также методы анализа деятельности человека с точки зрения определения мотиваций. В масштабах всей экономики ничем принципиально измерение доверия не отличается - измерения проводятся либо через опросы («эмоциональнопсихологическая методика построения индекса доверия»), либо через анализ фактических данных («экономическая методика построения индекса доверия»).

Как отмечают исследователи [39, с. 84], у каждой из этих методик есть свои достоинства и недостатки. Эмоциональнопсихологическая ценна тем, что позволяет оценить мотивацию субъекта при принятии тех или иных решений, то есть понять, как воспринимается ситуация потребителями, большинство из которых не являются профессиональными экономистами. Это крайне важно для формирования политики построения доверия. По этой методике не просто фиксируется изменение доверия, но и определяются причины этого изменения, в отличие от анализа фактических данных, где при фиксации самого изменения причины его остаются неясными. Это определяет повышенное внимание к эмоциональнопсихологической методике со стороны компаний и правительств, заинтересованных в быстрых ответных действиях на снижение доверия, где быстрота напрямую зависит от информированности о причинах снижения.

Другой важный момент - принципиальный субъективизм доверия. В силу того, что это ожидание иррационально, весьма трудно изменить мнение людей о наличии или отсутствии доверия. Если люди уверены, что в экономических отношениях нет доверия, никакие цифры и факты не убедят их в обратном. Их мнение о доверии будет актом веры в собственные представления, в итоге доверие действительно будет исчезать, раз уж в экономических отношениях агенты будут действовать, как будто его не существует. С другой стороны, если изза религиозных или культурных влияний люди будут полагать доверие в экономических отношениях высоким, то их действия и приведут к реальному повышению уровня доверия.

Из этого утверждения выводится наша уверенность в том, что для измерения доверия эмоционально-психологическая методика построения индекса доверия, кажущаяся менее точной, будет все же верней экономической методики построения индекса доверия. Немалым достоинством эмоционально-психологической методики является ее простота по сравнению с выстраиванием сложных математических моделей с кучей переменных. В качестве при- 
мера применения этой методики укажем на индекс доверия к брендам компаний, который составляет РОМИР - крупнейший российский холдинг, специализирующийся на исследованиях различных рынков и сфер жизни общества. Для измерения доверия им используется GRI (Global Reputation Index), который базируется на интегрированном подходе, включающем в себя анализ присутствия компании в медиапространстве (что люди говорят о вас?) и опрос ключевых экспертов рынка, клиентов, партнеров (что люди думают о вас?). На основе полученных данных рассчитываются Индекс заметности компании и Индекс доверия - насколько компании доверяют. Составление подобных индексов вполне доступно любой компании самостоятельно через опросы партнеров и потребителей и анализ упоминаний и отзывов в прессе и Интернете.

Е.В. Балацкий выделяет еще один важнейший признак доверия - глубину горизонта планирования действий [40, с. 75-79]. Чем больше компания доверяет и чем больше доверяют ей, тем значительней ее горизонты планирования и тем больше горизонты планирования сотрудничества с ней ее партнеров и потребителей. Соответственно, успешность построения доверия компании будет определяться тем, насколько долговременные отношения готовы выстраивать с компанией ее партнеры, на сколько лет вперед заключают с ней контракты потребители и на сколько лет вперед планируется сотрудничество и взаимодействие с органами власти и конкурентами.

Конкуренция за доверие в российской экономике: состояние и перспективы

В российской экономике доверие до сих пор не воспринимается как ценность, нематериальный актив компании или хотя бы как конкурентное преимущество. Разумеется, как предприниматели, так и чиновники уже знают о роли доверия в экономике и обществе, благо об этом все больше пишут и еще больше говорят. Была даже оформ- лена законодательная база для построения доверия через раздел в «Концепции долгосрочного социально-экономического развития Российской Федерации на период до 2020 года», разработанной Минэкономразвития и принятая распоряжением правительства РФ от 17 ноября 2008 г. № 1662-р. В целевых ориентирах этой концепции прямо указывается: «В России сформируется общество, основанное на доверии и ответственности, включая доверие населения к государственным и частным экономическим институтам».

Высокое доверие граждан к государственным и общественным институтам увязывается в концепции с эффективно работающей демократической системой, которая обеспечивает не только свободу частных интересов и договорных отношений, но и создает предпосылки для активизации инновационных процессов. Однако все это осталось благими пожеланиями на бумаге. Ни государство, ни сами компании по-прежнему не видят большого смысла в усилиях по достижению доверия. Тем более что в условиях нерыночной конкуренции доверие зачастую действительно для российской компании не является первоочередной задачей и особой ценностью. При этом развитие экономических отношений приводит к тому, что потребности прогрессируют и усложняются [41], так что потребность в доверии неизбежно будет все более ощутимой.

Невнимание к доверию сказывается в развитии в России брендов. Аналитики отмечают слабость российских брендов: хотя совокупная стоимость вошедших в топ-40 самых дорогих марок России брендов оценивается в 2,6 трлн руб., некоторые крупнейшие компании имеют минимальную долю стоимости бренда в капитализации [42]. До 2008 г. российских представителей в глобальном рейтинге ста самых дорогих глобальных брендов не было. В 2014 г. в рейтинг Millward Brown попали бренды двух компаний: финансовая органи- 
зация «Сбербанк» (75 место; \$12,637 млрд) и оператор сотовой связи МТС (принадлежит ОАО «Мобильные ТелеСистемы») (80 место; \$12,175 млрд). Хотя Сбербанк стал самым дорогим российским брендом, однако его стоимость по сравнению с 2013 г. не изменилась [8]. Подобный скромный результат российских компаний во многом вызван, без всяких сомнений, слабостью их репутаций на домашнем рынке и низким доверием россиян к компаниям.

Неудачи брендинга первых лет построения рынка еще можно было списать на оставшееся от позднего СССР более высокое доверие к качеству западной продукции и западным торговым маркам. Однако более чем за двадцать лет можно было добиться коренного изменения в мировоззрении людей. Тем не менее этого не произошло. Несмотря на стабильность 2000-х гг., уже первые кризисные явления 2008-2009 гг. обрушили доверие россиян к бизнесу. Если общемировой тенденцией было быстрое восстановление доверия, то, по результатам исследования Elderman Trust Barometer 2010 г., число россиян, доверяющих бизнесу, продолжало падать - доверие испытывали только $42 \%$ опрошенных [43].

Еще до введения санкций протии России со стороны западных стран, в марте 2014 г., экономисты Всемирного банка опубликовали очередной доклад об экономике России [43] с символичным названием «Кризис доверия обостряет экономические проблемы России». В докладе доказывается, что, в то время как идет восстановление экономик стран после кризиса 2008 г., российская экономика в 2013 г. охвачена кризисом доверия, снизилось потребление и уровень загрузки производственных мощностей, идет ухудшение предпринимательской уверенности, что резко снижает инвестирование. Политический кризис 2014 г. и стремительное падение курса рубля лишь наложились на уже сформировавшийся кризис.

Одной из причин кризиса доверия в России является нежелание и неумение сотрудничать с конкурентами, хотя коопетиция в зарубежных странах приобретает все больший размер. Российские компании по-прежнему ориентированы на завоевание благосклонности чиновников, а не потребителей. Этому свидетельство постоянные коррупционные скандалы в российской экономике и активное участие самих чиновников или же их ближайших родственников в управлении частных компаний. В то же время на Западе усиливаются стандарты корпоративной этики для завоевания доверия инвесторов и потребителей. Как отмечает А. Заман, этические моменты все в большей степени становятся составной частью корпоративного бренда, во многом благодаря росту социальных ожиданий от компаний [23, с. 37].

В России же такие крупнейшие компании, как ВТБ и «Роснефть», имеют минимальную долю стоимости бренда в капитализации (на уровне 1 \%), что делает для них излишними какие-либо усилия для завоевания доверия или поиска способов обретения социального капитала. Неудачи преследуют российские компании и в завоевании доверия зарубежных инвесторов, поставщиков и партнеров. Особенно заметно терял доверие «Газпром» из-за срыва поставок и участия в политическом давлении на правительства европейских стран. На фоне катастроф доверия на внешних рынках усилия «Газпрома» по завоеванию доверия отечественных потребителей (для которых компания зачастую безальтернативный поставщик газа) и граждан выглядят не слишком нужными.

Единственным значимым успешным примером совместных усилий по коопетиции в области сохранения и поддержания доверия стала в России банковская сфера. После дефолта 1998 г. доверие к банкам в целом было стабильно низким, что всерьез беспокоило как банкиров, так и экономистов, предсказывающих нестабильность экономического развития России при таком низком доверии к финансовым институтам. 
Поэтому непосредственно после дефолта началась выработка как государственной политики наведения порядка в банковской сфере, так и создание соглашений между банками по налаживанию сотрудничества и совместному построению доверия. В результате целого комплекса мер по государственным гарантиям защиты вкладов, с поддержкой частных банков государственными программами и с координацией усилий самих частных банков по сохранению имиджа отдельных банков и российской банковской системы в целом кризис доверия удалось преодолеть.

Успехами в налаживании сотрудничества и в достижении доверия могут гордиться и некоторые крупные компании. В Уральском регионе особо стоит отметить Уральскую горно-металлургическую компанию (УГМК). Холдинг, являясь крупнейшим производителем меди в России, объединяет более 40 предприятий в различных регионах России и за рубежом. Помимо металлургии, УГМК имеет проекты в сферах сельского хозяйства, строительства и девелопмента, выходит на рынок телекоммуникационных, медицинских и страховых услуг. Такая крупная компания неизбежно должна выстраивать доверительные отношения не только с региональными и российскими властями, но и завоевывать доверие населения, особенно когда ряд ее проектов столкнулись с обвинениями в причинении экологического ущерба. Поэтому УГМК неизменно объявляет о своей ответственности за развитие территорий, где размещены предприятия холдинга, за социальное благополучие и повышение уровня материального благосостояния их жителей. Компания поддерживает образование, науку, культуру, искусство, спорт и здравоохранение, стремится брать в партнеры местные предприятия, устанавливая с ними долговременное и взаимовыгодное сотрудничество. Также УГМК участвует в региональных социальных программах, а также во всероссийских проектах, являясь, в частности, учредителем благотворительного фонда «Дети России» и спонсором баскетбольного клуба УГМК. В ходе подготовки Сочинской олимпиады 2014 г. УГМК принимала участие в строительстве олимпийских объектов, в 2012 г., завершив строительство Малой ледовой арены на 7000 мест, ставшей одной из шести арен Олимпийского парка. Широкую известность по всей России получил созданный компанией в г. Верхняя Пышма Музей военной техники «Боевая слава Урала».

Значимо участие УГМК в совместной программе подготовки кадров промышленных работников в сотрудничестве с властями Свердловской области и другими компаниями. В 2013 г. был открыт корпоративный Технический университет УГМК (г. Верхняя Пышма), в совместных проектах по «Уральской инженерной школе» созданы центры инженерного творчества для школьников в городах Свердловской области. Подобные усилия компании по развитию края и завоеванию доверия населения заслуживают наивысшей оценки и могут стать хорошими примерами для подражания другим крупным компаниям. Будет справедливым утверждать, что УГМК успешно конкурирует за доверие не только партнеров по бизнесу, но и населения.

Однако даже крупнейшие компании сообща не смогут обойтись в построении доверия без сотрудничества с государством. Из-за российских реалий и высокой доли государственного участия в экономике невозможно представить, чтобы государство и дальше оставалось в стороне от создания и поддержания доверия в экономике. Предотвратить кризис доверия мерами государственного управления было вполне возможно [44] прежде всего через организацию сотрудничества компаний в национальных высокотехнологичных проектах, развитие кооперации, инновационных совместных производств, через завоевание и удержание доверия населения к органам власти и компаниям. К сожалению, ничего этого не было сделано. Известный экономист Михаил Де- 
лягин справедливо считает, что в современном кризисе можно видеть дефолт доверия к российской власти [45]. Можно добавить, что имеется и дефолт доверия российских компаний, симптомами чему является широко обсуждаемые события вокруг АФК «Система», «Мечела» и «Роснефти». Если крупные компании позиционируют себя как национальные, то этот статус они должны поддерживать через завоевание социального капитала и доверия общества, через налаживание сотрудничества друг с другом и в изменении отношений к торговым маркам и нематериальным активам. Без подобных усилий кризис, начавшийся в 2014 г., будет затяжным и разрушительным.

\section{Выводы}

Анализ опыта построения доверия в западных компаниях позволяет дать несколько рекомендаций по оптимальным тактикам успеха в конкурентной борьбе за доверие. Конкурируя за доверие, не стоит использовать методы, которыми доверие подрывается, тем более что процветание компании все больше в современной экономике зависит от взаимодействия с конкурентами. Распространение ложной информации о конкурентах, подкуп власти и прессы, обман потребителей о качестве и характеристиках своих товаров и услуг могут принести выгоды в ближайшем будущем, но полностью разрушат доверие к компании в дальнейшем. При обилии информации мир становится все более «прозрачным» и обману все трудней остаться незамеченным. Честность - лучшая и самая недорогая политика в достижении доверия.
Крайне затратными, но столь же крайне необходимыми для завоевания доверия являются способы продвижения компании в медиапространстве. Благотворительность, участие в совместных социальных программах с органами власти, поддержка культурных мероприятий способствуют частоте упоминания компании в прессе и формируют доверие к ней населения. Увеличению узнавания компании в узкопрофессиональной среде способствует участие компаний в выставках, профессиональных конференциях, постоянная работа в профессиональных объединениях в рамках своей отрасли и в торгово-промышленных палатах. Именно в рамках таких объединений может быть налажено и скоординировано конкурентное сотрудничество, выработаны общие правила игры, определены цели и задачи, перспективы развития отрасли.

Важнейшим фактором успеха в конкурентной борьбе за доверие становится способность компании предвидеть будущие технологические и организационные изменения, опережая соперников в глубине горизонта планирования. Здесь эффективны как конкурентное сотрудничество в научнотехническом прогрессе и в совместном внедрении новых технологий, так и конкурентная разведка, ориентированная на изучение сильных и слабых сторон конкурентов, не идущих на сотрудничество. Так как доверие не только выгодно, но и увеличивает риски, анализ эффективности действий соперников и лояльности партнеров, измерение доверия к компании как показатель успешности выбранной ей стратегии будут необходимы для жизнестойкости компании.

\section{Список использованных источников}

1. Портер М. Конкуренция. Обновленное и расширенное издание. М.: ООО «И.Д. Вильямс», 2010.

2. Робинсон Дж. Экономическая теория несовершенной конкуренции. М.: Прогресс, 1986.
3. Важенина И.С. Деловая репутация как конкурентный ресурс компании // Журнал экономической теории. 2006. № 4. C. 134-150.

4. Важенина И.С. Имидж и репутация организации: экономическое содержание, формирование и оценка // Марке- 
тинг в России и за рубежом. 2010. № 2 . С. 136-143.

5. Ли Куан Ю. Сингапурская история. 1965-2000 гг. Из третьего мира в первый. М.: МГИМО-Университет, 2010.

6. Кови-мл. С., Меррил Р. Скорость доверия. То, что меняет всё. М.: Альпина Паблишер, 2010.

7. Бардина К. В России уровень доверия к бизнесу по прежнему ниже, чем в Европе и США. [Электронный ресурс]. Режим доступа: http://finam.ru.

8. Millward Brown: Рейтинг 100 caмых дорогих мировых брендов 2014 года. [Электронный ресурс]. Режим доступа: http:/gtmarket.ru/ news/2014/05/21/6779.

9. Fukuyama F. Trust: The Social Virtues and the Creation of Prosperity. NewYork: FreePress, 1995.

10. Gambetta D. Trust: Making and Breaking Cooperative Relations. Oxford: Blackwell, 1998.

11. Castaldo S. Trust In Market Relationships. Cheltenham, UK; Northampton. MA, USA: Edward Elgar Publishing, 2008.

12. Штомпка П. Доверие - основа общества. М.: Логос, 2012.

13. Экономика и социология доверия. СПб.: Социол. об-во им. М.М. Ковалевского, 2004.

14. Ходжсон Дж. Экономическая теория и институты: Манифест современной институциональной экономической теории. М.: Дело, 2003.

15. Клейнер Г. Стратегический менеджмент: актуальные проблемы и новые наравления // Проблемы теории и практики управления. 2009. № 1. С. 15-22.

16. Важенин С.Г., Сухих В.В., Бурьков С.М. Интернационализация доверия // Вестник УрФУ. Серия экономика и управление. 2013. № 5. С. 65-72.

17. Ольсевич Ю.Я. Фундаментальная неопределенность рынка и концепции современного кризиса. М.: Институт экономики РАН, 2011.

18. Алле М. Экономика как наука. М.: РГГУ, 1995.
19. Совершенство каменных орудий связали с репутацией. [Электронный ресурс]. Режим доступа: http://lenta.ru/ news/2012/11/21/trustaxe/.

20. Важенин С.Г., Сухих В.В. Доверие в российской торгово-промышленной среде ХІХ-XX веков // ЭКО. 2006. № 6. С. 168-182.

21. Важенин С.Г., Сухих В.В. Доверие в торговых традициях исламских стран // ЭКО. 2010. № 7. С. 136-147.

22. Буари Ф. Паблик рилейшнз или стратегия доверия. М.: Инфра-М, 2001.

23. Заман А. Репутационный риск: управление в целях создания стоимости. М.: Олимп-бизнес, 2008.

24. Радаев В.В. Социология рынков: к формированию нового направления. М.: ГУ ВШЭ, 2003.

25. Бранденбургер А., Нейлбафф Б. Соopetition. Конкурентное сотрудничество в бизнесе. М.: ООО «Кейс»: ООО «Омега-Л», 2012.

26. Локке Р.М. Формирование доверия. М.: ГУ ВШЭ, 2005.

27. Рубин Ю.Б. Дискуссионные вопросы современной теории конкуренции // Современная конкуренция. 2010. № 3. C. 38-67.

28. Портер М. Конкурентное преимущество. М.: Альпина Бизнес Букс, 2005.

29. Деминг Э. Новая экономика. М.: Эксмо, 2006.

30. Корнаи Я. Честность и доверие в переходной экономике // Вопр. экономики. 2003. № 9. С. 4-17.

31. Ленин В.И. Очередные задачи Советской власти // В.И. Ленин. Полное собрание сочинений. Изд-е пятое. М.: Издво полит. литературы, 1981. Т. 36.

32. Эрхард Л. Благосостояние для всех. М.: Начала-Пресс, 1991.

33. Восстановление доверия к южнокорейской экономике // Самые успешные PR-компании в мировой практике. М.: ИНФРА-М, 2002. С. 157-162.

34. Создание доверия на новом этапе деятельности компании // Самые успешные PR-компании в мировой практике. М.: ИНФРА-М, 2002. С. 75-80. 
35. Сибиряк С. В Давосе будут строить доверие. [Электронный ресурс]. Режим доступа: http:/gazeta. ru / 2003/ 01/23/.

36. World Economic Forum Annual Meeting 2010: Rebuilding Trust in Business Leadership. [Электронный ресурс]. Режим доступа: http://www.weforum. org/sessions/summary/rebuilding-trustbusiness-leadership.

37. The Leadership, Trust and perfomance equation. [Электронный ресурс]. Режим доступа: http://www.weforum. org/projects/leadership-trust-andperformance-equation.

38. Купрейченко А.Б. Психология доверия и недоверия. М.: Ин-т психологии PAH, 2008.

39. Николаев И, Ефимов С., Марушкина Е. Доверие как экономическая категория // Общество и экономика. 2006. № 1. C. 75-104.

40. Балацкий Е.В. Рынок доверия и национальные модели корпоративного сектора экономики // Общество и экономика. 2009. № 2. С. 59-80.

41. Важенина И.С. Возвышение потребностей и тупики потребления // ЭКО. 2012. № 11. C. 131-144.

42. Гуриев С., Качинс Э., Ослунд А. Россия после кризиса. М.: Юнайтед Пресс, 2014.

43. Россия: укрепление доверия. Развитие финансового сектора в России. М.: Весь мир, 2002.

44. Татаркин А.И., Сухих В.В., Важенин С.Г. Государство в системе отношений доверия в экономике // Общество и экономика. 2006. № 10. C. $155-172$.

45. Делягин М. Дефолт доверия. [Электронный ресурс]. Режим доступа: $\quad$ http://svpressa.ru/politic/ article $/ 107500 /$ ?redtrs $=1$.

Vazhenin S.G., candidate of economic sciences, Sookhikh $\boldsymbol{V} . \boldsymbol{V}$., candidate of economic sciences, Institute of Economics,

The Ural Branch of Russian Academy of Sciences, Ekaterinburg, Russia

\section{SPECIFICITY OF TRUST AS A COMPETITIVE GOAL IN THE ECONOMY}

Increased competition forces companies to seek new competitive advantages. Since the abundance of information and supply makes it difficult for consumers and potential partners to choose a particular product or a particular company, a unique image of the company recognizable by customers and partners becomes the most important competitive advantage that can set the company and its products or services apart among numerous other offerings on the market. This image is largely determined by trust to the company. Trust becomes a critical resource to compete for not only for companies, but also for countries. The article defines the concept of «competition for trust» and considers the specifics of trust in the economy as a competitive goal. Its specificity is determined by the fact that trust is a behavioral characteristic; it has not only economic, but also psychological significance. Trust is irrational, it is a mutual feeling and requires mutual effort. The company will not be able to gain the trust of others, if at the same time it refuses to trust its partners and customers. Trust, being an irrational expectation, is inextricably linked with risk. There is always the possibility of unintended destruction of trust in the company. Trust easily disappears, but it is able to recover, unlike other resources we spend. In this case, trust can be an unlimited resource available to several competitors that provides the basis for their cooperation. Competitive cooperation enables companies to profit from an increase in confidence in the industry as a whole, avoiding the risk of loss in competition. The article also examines the specifics of measuring trust, assesses the state of and prospects for competition for trust in the Russian economy. Analysis of the experience of building trust in Western companies made it possible to give some advice on the best tactics for success in the competition for trust.

Key words: trust, competition, competitive goal, coopetition, cooperation. 


\section{References}

1. Porter, M. (2008). On Competition, Updated and Expanded Edition. Harvard Business Review Press (Rus. ed.: Porter, M. (2010). Konkurentsiia. Obnovlennoe $i$ rasshirennoe izdanie. Moscow, Williams Publ.).

2. Robinson, J. (1969). The Economics of Imperfect Competition. London, Macmillan. (Rus. ed.: Robinson, Dzh. (1986). Ekonomicheskaia teoriia nesovershennoi konkurentsii. Moscow, Progress).

3. Vazhenina, I.S. (2006). Delovaia reputatsiia kak konkurentnyi resurs kompanii [Business reputation is the competitive resource of the company]. Zhurnal ekonomicheskoi teorii [Russian Journal of Economic Theory], No. 4, 134-150.

4. Vazhenina, I.S. (2010). Imidzh i reputatsiia organizatsii: ekonomicheskoe soderzhanie, formirovanie i otsenka [Image and reputation of the organization: the economic content, formation and estimation]. Marketing $v$ Rossii $i \quad z a$ rubezhom [Marketing in Russia and abroad], No. 2, 136-143.

5. Lee Kuan Yew (2000). The Singapore Story: 1965-2000: From Third World to First. Harper. (Rus.ed.: Li Kuan Iu (2010). Singapurskaia istoriia. 1965$2000 \mathrm{gg}$. Iz tret'ego mira $v$ pervyi. Moscow, MGIMO-University).

6. Covey, S., Merill, R. (2006). The Speed of Trust: The One Thing that Changes Everything. NY, Free Press. (Rus. ed.: Kovi-ml., S., Merril, R. (2010) Skorost' doveriia. To, chto meniaet vse. Moscow, Alpina Publ.).

7. Bardina, K. V Rossii uroven' doveriia $k$ biznesu po prezhnemu nizhe, chem $v$ Evrope i SShA [Trust in business in Russia is still lower than in Europe and USA]. Available at: http://finam.ru.

8. Millward Brown: Top 100 Most Valuable Global Brands 2014. Available at: http:// gtmarket.ru/news/2014/05/21/6779.
9. Fukuyama, F. (1995). Trust: The Social Virtues and the Creation of Prosperity. New York, FreePress.

10. Gambetta, D. (1998). Trust: Making and Breaking Cooperative Relations. Oxford, Blackwell.

11. Castaldo, S. (2008). Trust In Market Relationships. Cheltenham, UK, Northampton. MA, USA, Edward Elgar Publishing.

12. Sztompka, P. (2007). Zaufanie: Fundament spoleczenstwa. Warsaw, Znak. (Rus.ed: Shtompka, P. (2012). Doverie - osnova obshchestva. Moscow, Logos).

13. Ekonomika i sotsiologiia doveriia [Economics and sociology of trust]. 2004, St Petersburg, Kovalevskii Sociological Society.

14. Hodgson, G. (1988). Economics and Institutions: A Manifesto for a Modern Institutional Economics. Philadelphia, University of Pennsylvania Press. (Rus. ed.: Khodzhson, Dzh. (2003). Ekonomicheskaia teoriia $i$ instituty: Manifest sovremennoi institutsional'noi ekonomicheskoi teorii. Moscow, Delo).

15. Kleiner, G. (2009). Strategicheskii menedzhment: aktual'nye problemy i novye napravleniia [Strategic management: present-day issues and new trends]. Problemy teorii i praktiki upravleniia [Problems of theory and practice of management], No. 1, 15-22.

16. Vazhenin, S.G., Sukhikh, V.V., Bur'kov, S.M. (2013). Internatsionalizatsiia doveriia [Internationalization of trust in the economy]. Vestnik UrFU. Seriia ekonomika $i$ upravlenie [Bulletin of UrFU. Series economics and management], No. 5, 65-72.

17. Ol'sevich, Iu.Ia. (2011). Fundamental'naia neopredelennost' rynka i kontseptsii sovremennogo krizisa [Fundamental uncertainty in the market and concepts of modern crisis]. Moscow, Institute of Economics of the Russian Academy of Sciences. 
18. Allais, M. (1943). À la recherche d'une discipline économique. (Rus. ed.: Alle, M. (1995). Ekonomika kak nauka. Moscow, RGGU).

19. Sovershenstvo kamennykh orudii sviazali $\mathrm{s}$ reputatsiei [Link found between perfection of stone tools and reputation]. Available at: http://lenta.ru/ news/2012/11/21/trustaxe/.

20. Vazhenin, S.G., Sukhikh, V.V. (2006). Doverie V rossiiskoi torgovopromyshlennoi srede XIX-XX vekov [Confidence in the Russian commercial and industrial environment of XIX - early XX centuries]. EKO, No. 6, 168-182.

21. Vazhenin, S.G., Sukhikh, V.V. (2010). Doverie $\mathrm{V}$ torgovykh traditsiiakh islamskikh stran [Confidence in trade traditions of Islamic countries]. EKO, No. 7, 136-147.

22. Boiry, P. (1989). Les relations publiques: ou la stratégie de la confiance. Paris, Eyrolles. (Rus.ed.: Buari, F. (2001). Pablik rileishnz ili strategiia doveriia. Moscow, INFRA-M).

23. Zaman,A.(2003). Reputational Risk: How to Manage for Value Creation. London, Financial Times Management. (Rus.ed.: Zaman, A. (2008). Reputatsionnyi risk: upravlenie $v$ tseliakh sozdaniia stoimosti. Moscow, Olimp-biznes).

24. Radaev, V.V. (2003). Sotsiologiia rynkov: $k$ formirovaniiu novogo napravleniia [Sociology of markets: toward creation of a new trend]. Moscow, Higher School of Economics.

25. Brandenburger, A., Nalebuff, B. (1997). Co-Opetition. Currency Doubleday. (Rus. ed.: Brandenburger, A., Neilbaff, B. (2012). Co-opetition. Konkurentnoe sotrudnichestvo v biznese. Moscow, Keys).

26. Locke, R. (2005). Formirovanie doveriia [Building Trust]. Moscow, Higher School of Economics.

27. Rubin, Iu.B. (2010). Diskussionnye voprosy sovremennoi teorii konkurentsii [Discussion questions of modern competition theory]. Sovremennaia konkurentsiia [Journal of Modern Competition], No.3, 38-67.
28. Porter, M. (1998). Competitive Advantage: Creating and Sustaining Superior Performance. NY, Free Press. (Rus. ed.: Porter, M. (2005). Konkurentnoe preimushchestvo. Moscow, Alpina Biznes Buks).

29. Deming, W. (2000). The New Economics for Industry, Government, Education. MIT Press. (Rus. ed.: Deming, E. (2006). Novaia ekonomika. Moscow, Eksmo).

30. Kornai, J. (2003). Chestnost' i doverie $\mathrm{v}$ perekhodnoi ekonomike [Honesty and trust in a transitional economy]. Vorposy ekonomiki [Problems of economics], No. 9, 4-17.

31. Lenin, V.I. (1981). Ocherednye zadachi Sovetskoi vlasti [The immediate tasks of the Soviet government]. In Lenin V.I. Collected Works, Vol. 36. Moscow, Izdatel'stvo politicheskoi literatury.

32. Erhard, L. (1957). Prosperity Through Competition. (Rus. ed.: Erkhard, L. (1991). Blagosostoianie dlia vsekh. Moscow, Nachala-Press).

33. Restoring Economic Confidence in Korea during the Asian Financial Crisis. In SO08 Silver Anvil Award. 1999. (Rus. ed.: Samye uspeshnye PR-kompanii v mirovoi praktike. 2002, Moscow, INFRA-M).

34. Sozdanie doveriia na novom etape deiatel'nosti kompanii [Building trust at a new stage in a company's operation]. In Samye uspeshnye PR-kompanii $v$ mirovoi praktike [The most successful PR campaigns in history]. 2002, Moscow, INFRA-M.

35. Sibiriak, S. VDavose budut stroit'doverie [Trust to be built at Davos]. Available at: http://gazeta. ru/2003/01/23/.

36. World Economic Forum Annual Meeting 2010: Rebuilding Trust in Business Leadership (2010). Available at: http://www.weforum.org/sessions/ summary/rebuilding-trust-businessleadership.

37. The Leadership, Trust and Perfomance Equation. Available at: http://www. weforum.org/projects/leadership-trustand-performance-equation. 
38. Kupreichenko, A.B. (2008). Psikhologiia doveriia $i$ nedoveriia [Psychology of trust and mistrust]. Moscow, Institute of Psychology of Russian Academy of Sciences.

39. Nikolaev, I, Efimov, S., Marushkina, E. (2006). Doverie kak ekonomicheskaia kategoriia [Trust as an economic category]. Obshchestvo $i$ ekonomika [Society and economy], No. 1, 75-104.

40. Balatskii, E.V. (2009). Rynok doveriia i natsional'nye modeli korporativnogo sektora ekonomiki [Market of trust and national models of corporate sector of the economy]. Obshchestvo i ekonomika [Society and economy], No. 2, 59-80.

41. Vazhenina, I.S. (2012). Vozvyshenie potrebnostei i tupiki potrebleniia [Growing needs and dead ends of consumption]. EKO, No. 11, 131-144.
42. Guriev, S., Kuchins, A., Aslund, A. (2014). Rossiia posle krizisa [Russia After the Global Economic Crisis]. Moscow, Iunaited Press.

43. Rossiia: ukreplenie doveriia. Razvitie finansovogo sektora $v$ Rossii [Russia: building trust. Development of financial sector in Russia]. 2002, Moscow, Ves mir.

44. Tatarkin, A.I., Sukhikh, V.V., Vazhenin, S.G. (2006). Gosudarstvo v sisteme otnoshenii doveriia $\mathrm{v}$ ekonomike [State in the system of trust relationship in an economy]. Obshchestvo $i$ ekonomika [Society and economy], No. 10, 155-172.

45. Deliagin, M. Defolt doveriia [Defaul on trust]. Available at: http://svpressa.ru/ politic/article/107500/?redtrs $=1$.

\section{Information about the authors}

Vazhenin Sergei Grigorievich - Candidate of Economic Sciences, Head of Sector, Institute of Economics, The Ural Branch of Russian Academy of Sciences, Ekaterinburg, Russia (620014, Ekaterinburg, Moskovskaya street, 29); e-mail: svazhenin@mail.ru.
Sookhikh Vasili Valentinovich - Candidate of Economic Sciences, Research Associate, Institute of Economics, The Ural Branch of Russian Academy of Sciences, Ekaterinburg, Russia (620014, Ekaterinburg, Moskovskaya street, 29); e-mail: vsh-sh@yandex.ru. 